NISTIR 6728

\title{
NIST Multizone Modeling Website
}

\author{
W. Stuart Dols
}
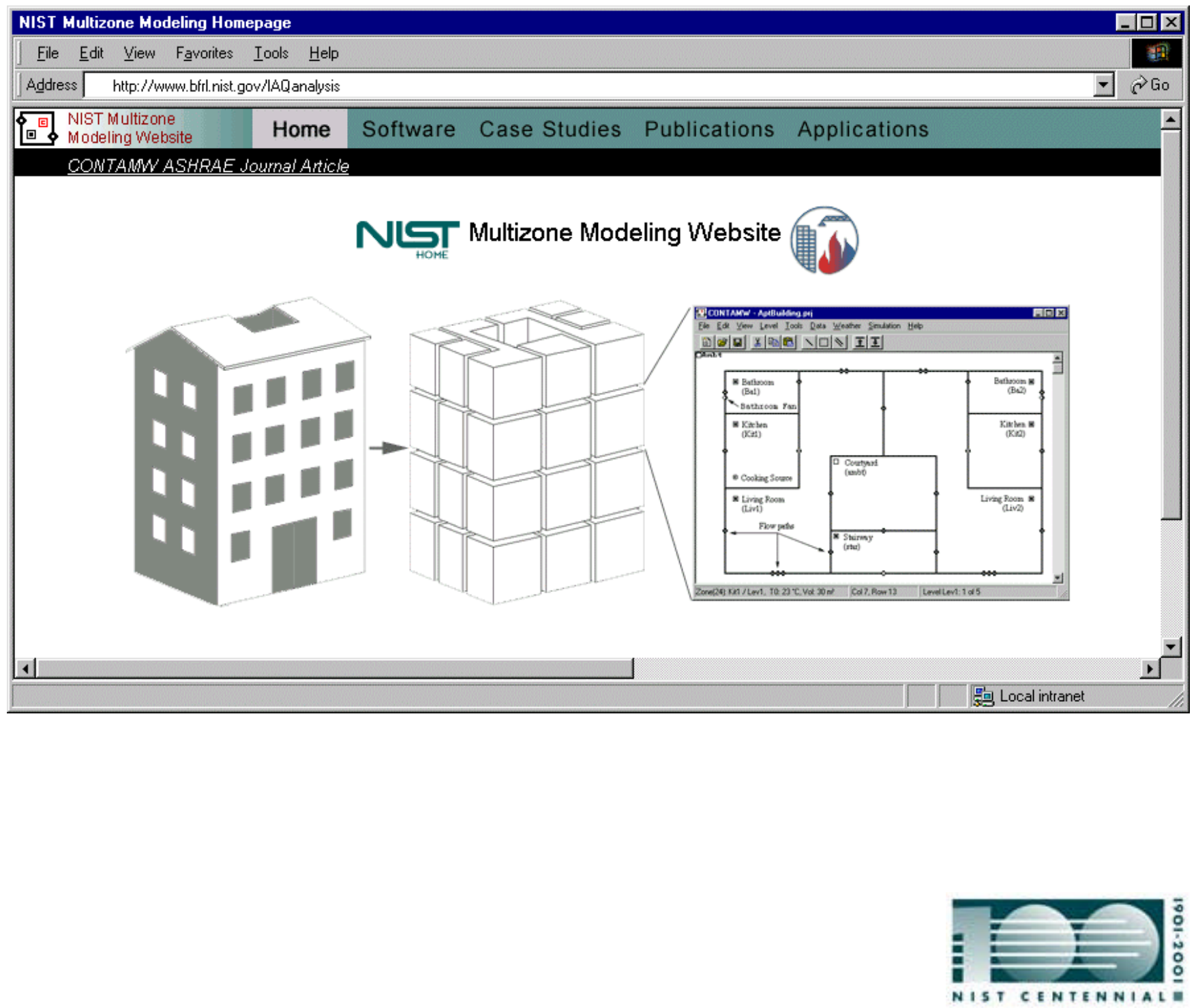

NIT

National Institute of Standards and Technology Technology Administration, U.S. Department of Commerce 


\section{NIST Multizone Modeling Website}

W. Stuart Dols

Building Environment Division Building and Fire Research Laboratory National Institute of Standards and Technology

Gaithersburg, MD 20899-8633

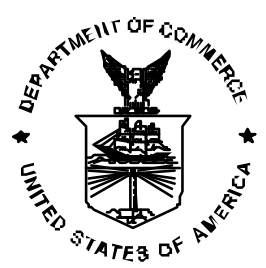

U.S. Department of Commerce Donald Evans, Secretary

National Institute of Standards and Technology Dr. Karen H. Brown, Acting Director 




\section{Abstract}

This report presents an overview of the NIST Multizone Modeling Website developed by the Building and Fire Research Laboratory of the National Institute of Standards and Technology (NIST). Multizone modeling refers to the calculation of airflows, pressure differences and contaminant transport between zones and across the envelope of a building based on a simplified macro-representation of the building. This website was established to foster the development and facilitate the application of multizone ventilation and indoor environmental modeling in the areas of building design, operation, maintenance, investigation and research. The main component of this website is the multizone airflow and ventilation modeling software CONTAMW. Within this website you will find software tools for performing multizone analysis, including CONTAMW; CONTAMW data input libraries; information on the applications of multizone modeling; multizone modeling case studies; and references to multizone modeling publications.

Key Words: airflow analysis; building technology; computer programs; contaminant dispersal; indoor air quality; multizone analysis; smoke control; ventilation; website 



\section{Disclaimer}

The Department of Commerce makes no warranty, expressed or implied, to users of the software provided on this website, and accepts no responsibility for its use. Users of the software provided on this website assume sole responsibility under Federal and State law for determining the appropriateness of its use in any particular application; for any conclusions drawn from the results of its use; and for any actions taken or not taken as a result of analyses performed using the software provided on this website.

Users are warned that this software is intended for use only by persons competent in the field of airflow and contaminant dispersal in buildings and is intended only to supplement the judgment of the qualified user. The computer programs described in this report are prototype methodologies for computing the airflows and contaminant migration in a buildings. The calculations are based upon a simplified model of the complexity of real buildings. These simplifications must be understood and considered by the user.

Certain trade names and company products are mentioned in the text or identified in an illustration in order to adequately specify the equipment used. In no case does such an identification imply recommendation or endorsement by the National Institute of Standards and Technology, nor does it imply that the products are necessarily the best available for the purpose. 



\section{Table of Contents}

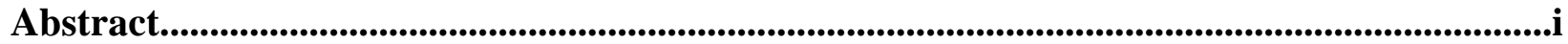

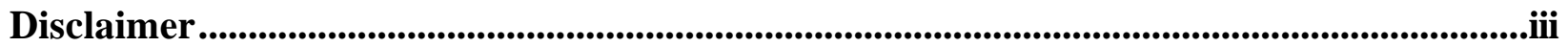

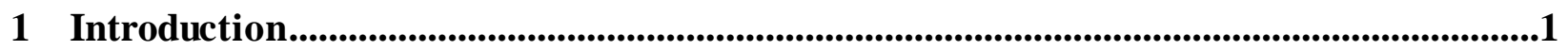

2 Multizone Analysis Software .............................................................................................2

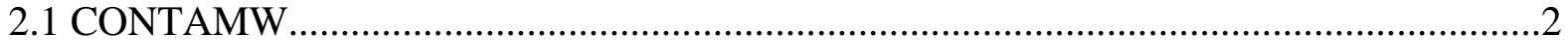

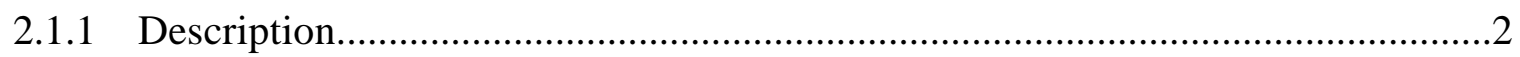

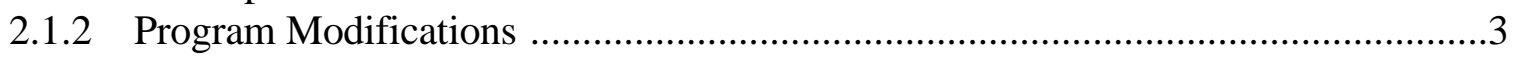

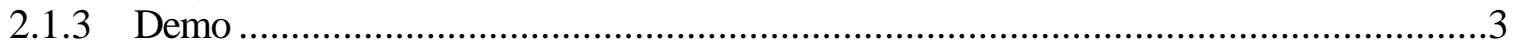

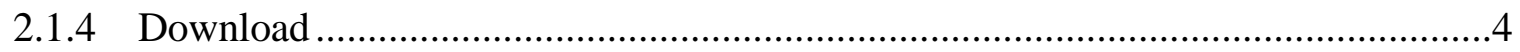

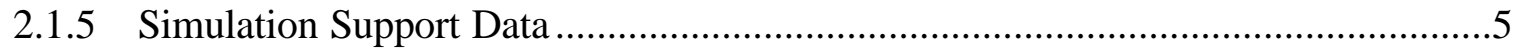

2.1.6 User Manual.............................................................................................

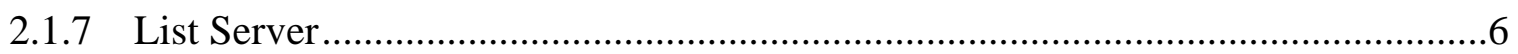

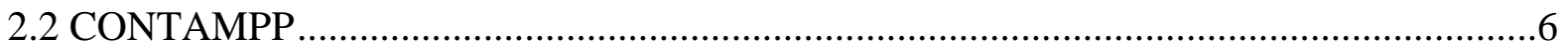

3 Applications of Multizone Modeling ..............................................................................7

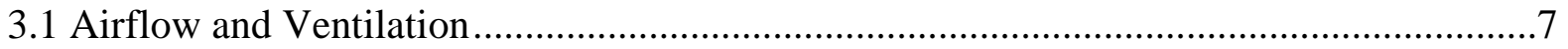

3.1.1 Building Air Change Rates .........................................................................

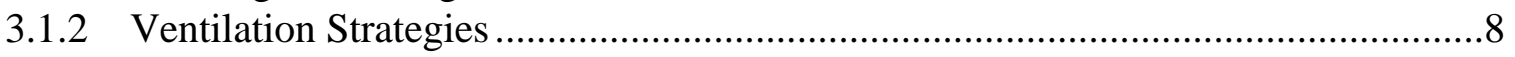

3.2 Indoor Air Quality Analysis and Contaminant Transport .......................................... 9

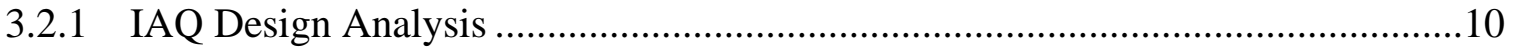

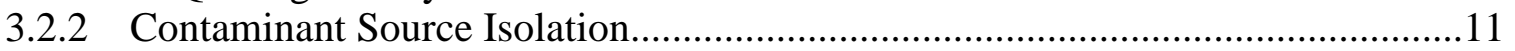

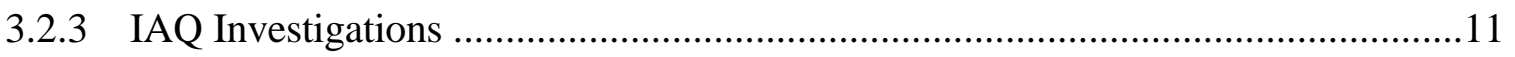

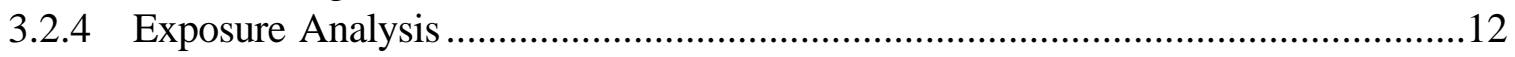

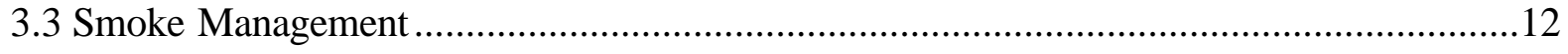

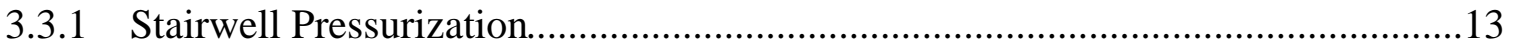

3.3.2 Zoned Smoke Control Systems .............................................................. 14

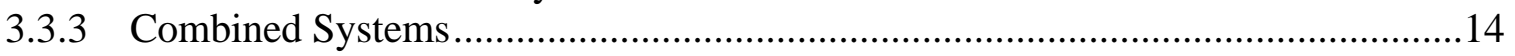

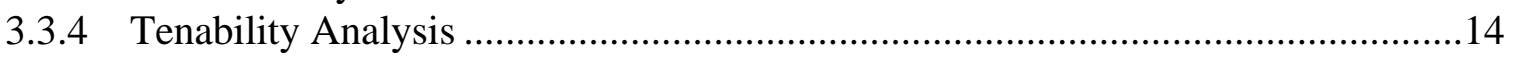

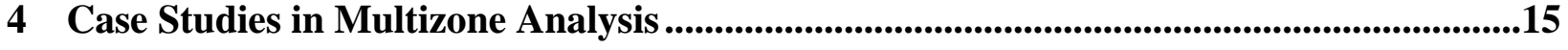

4.1 Ventilation in Manufactured Houses ........................................................................ 15

4.2 Ventilation, IAQ and Energy Impacts of Residential Mechanical Ventilation .................15

4.3 Energy Impacts of Infiltration and Ventilation in U.S. Office Buildings ........................16

4.4 Modeling of Three Residential IAQ Control Options ................................................17

4.5 IAQ Impacts of Particle Air Cleaners in a Single-zone Building ..................................17

4.6 Radon Transport in Large Buildings .................................................................... 18

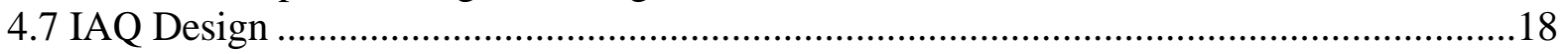

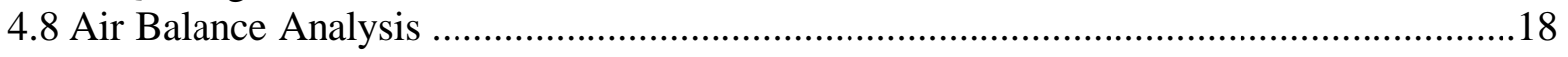

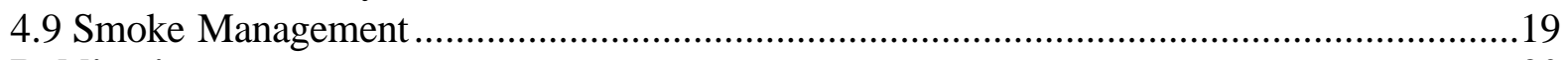

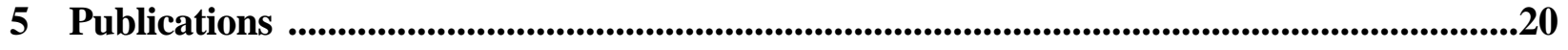

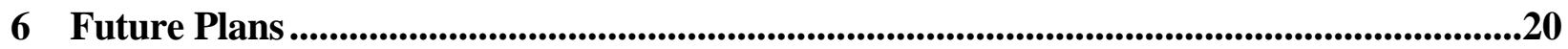

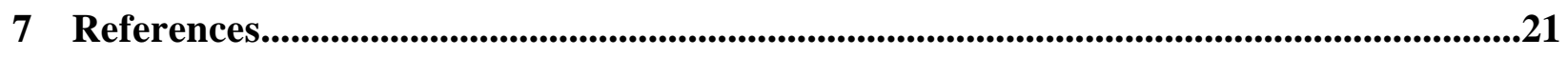

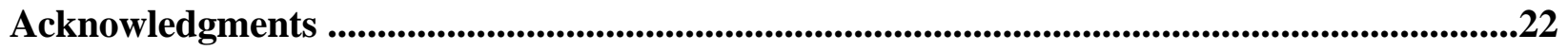





\section{Introduction}

The goal of the NIST Multizone Modeling Website is to foster the development and to facilitate the application of multizone ventilation and indoor environmental modeling in the areas of building design, operation, maintenance, investigation and research. Multizone modeling refers to the calculation of airflows, pressure differences and contaminant transport between zones and across the envelope of a building based on a simplified macro-representation of the building. Within this website are software tools (CONTAMW) for performing multizone analysis, information on the applications of multizone modeling, multizone modeling case studies, and references to multizone modeling publications.

This report presents the first generation of the website. A planned second generation will enhance the current website by providing more detailed methods of implementing the tools provided within the website, providing sample project files that demonstrate the use of the tools, increasing the amount of supporting data for the tools (e.g. data libraries) and the number of case studies in the application of multizone modeling.

The following site map is an overview of the pages contained within the website at the time of this publication. The table of contents of this publications reflects the website contents in even greater detail. The URL for the website is http://www.bfrl.nist.gov/IAQanalysis.

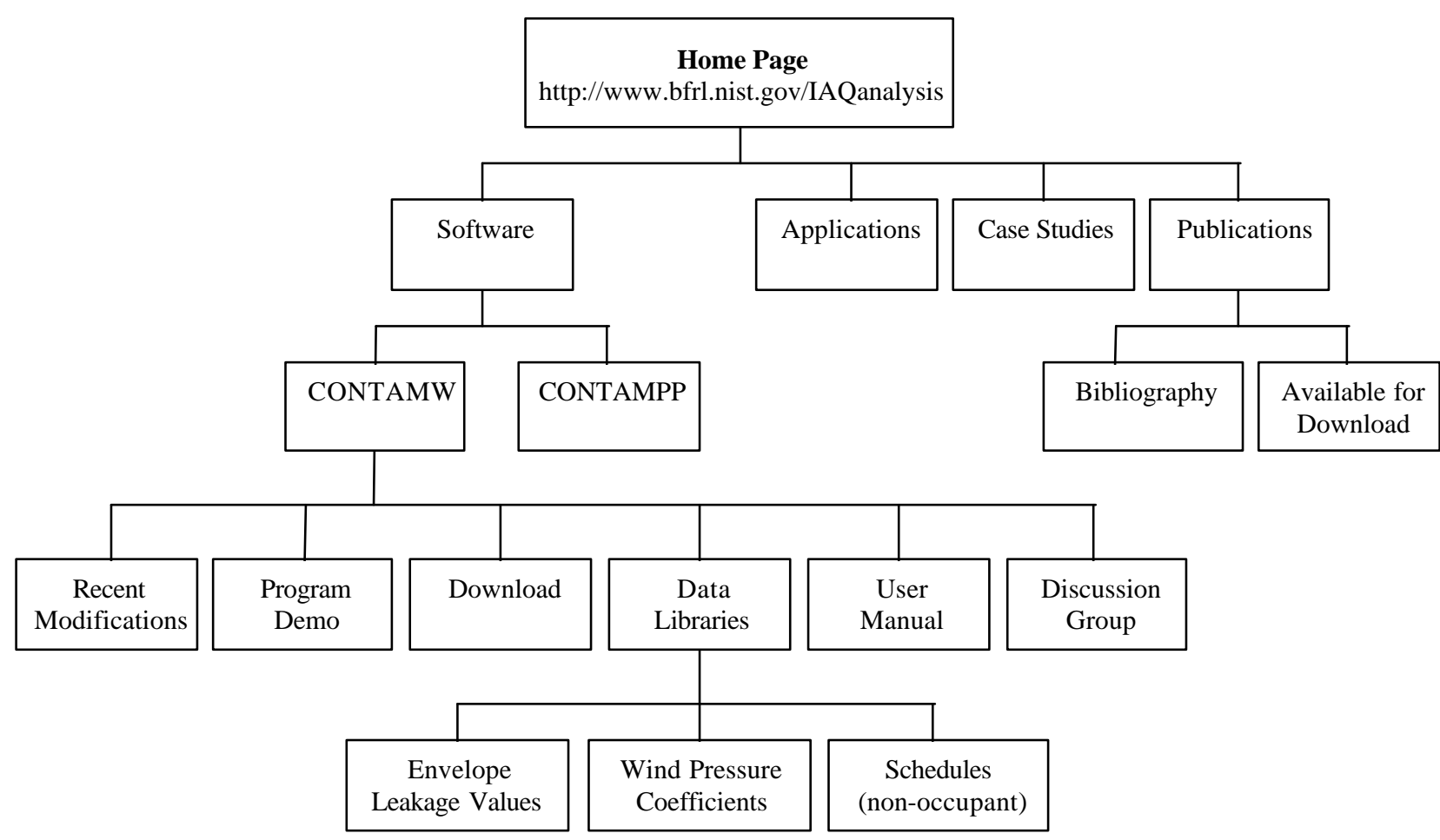

Figure 1 - Site Diagram 


\section{Multizone Analysis Software}

The website provides access to multizone analysis software programs that were developed by NIST. Software available includes: CONTAMW and CONTAMPP. CONTAMW is the multizone airflow and contaminant transport analysis program that is the main tool to be used in performing multizone analysis. CONTAMPP (CONTAM Post Processor) was designed to simplify the process of analyzing CONTAM simulation results.

Each program can be downloaded directly from the website for installation and execution on the user's computer. Specific instructions are given on the website for downloading each program.

\subsection{CONTAMW}

CONTAMW [Dols, Walton et al. 2000] is the main feature of the website. This program is the latest in the series of multizone analysis software developed by NIST. This section of the website includes pages for downloading the software, a list of recent modifications, an online demonstration of the major feature of the program, support data, user manual and access to a list server dedicated to the use of CONTAMW.

\subsubsection{Description}

CONTAMW is a multizone indoor air quality and ventilation analysis computer program designed to help you predict:

Airflows: infiltration, exfiltration, and room-to-room airflows in building systems driven by mechanical means, wind pressures acting on the exterior of the building, and buoyancy effects induced by the indoor and outdoor air temperature difference.

Contaminant Concentrations: the dispersal of airborne contaminants transported by these airflows; transformed by a variety of processes including chemical and radio-chemical reaction, adsorption and desorption to building materials, filtration, and deposition to building surfaces, etc.; and generated by a variety of source mechanisms, and/or

Personal exposure: the predictions of exposure of occupants to airborne contaminants for eventual risk assessment.

CONTAMW can be useful in a variety of applications. Its ability to calculate building airflows is useful to assess the adequacy of ventilation rates in a building, to determine the variation in ventilation rates over time and the distribution of ventilation air within a building, and to estimate the impact of envelope air tightening efforts on infiltration rates. The prediction of contaminant concentrations can be used to determine the indoor air quality performance of a building before it is constructed and occupied, to investigate the impacts of various design decisions related to ventilation system design and building material selection, and to assess the indoor air quality performance of an existing building. Predicted contaminant concentrations can also be used to estimate personal exposure based on occupancy patterns in the building being studied. Exposure estimates can be compared for different assumptions of ventilation rates and source strengths. 


\title{
2.1.2 Program Modifications
}

This page of the website provides information on the latest updates to the program including program enhancements and bug fixes. A table of modifications is presented that provides the type, description and date of the modifications.

\subsubsection{Demo}

This page provides access to an online "demo" of CONTAMW. This demo is an interactive overview of CONTAMW that was developed to show the main features of the program so users can get an idea of the program's capabilities before they download it.

The demo consists of a set of web pages that is controlled using a menu at the top of the screen or paging through it sequentially using buttons provided at the bottom of the screen.

The following is an outline of the online demo.

\author{
Introduction \\ What is CONTAMW? \\ User Tasks \\ Graphical User Interface (GUI) \\ CONTAMW Projects \\ Project Files \\ Building Components \\ Working with CONTAMW \\ SketchPad \\ Drawing walls and ducts \\ Drawing building components \\ Defining building components \\ Viewing results \\ Viewing wind effects \\ Airflow Paths \\ Mechanical Systems \\ Forced-flow models \\ Simple air handling systems \\ Duct systems \\ Contaminants \\ Sources and Sinks \\ Simulations \\ Simulation Results \\ SketchPad results \\ Graphing results
}




\subsubsection{Download}

To download the program, users must first fill out a registration form. The minimum amount of information that must be provided includes a contact name, company name, email address and type of business. This registration information is only used for purposes of contacting registered users of program updates or other special announcements related to multizone modeling. The information is not kept on computers that are accessible to the public and will not be distributed.

Upon completing this form a message will be displayed in the current browser window indicated that the registration information has been emailed to NIST, and a new browser window will be created that contains the actual web page from which the program download file can be obtained. The download file is an approximately two megabyte self extracting archive (CONTAMWZ.EXE) that is copied to the user's computer. Once downloaded, the user extracts the installation file by executing the self extracting archive, placing the files in the desired location within their computer directory structure, and executing the installation program SETUP.EXE. The following splash screen will appear briefly (Figure 2), and the user simply follows instructions, as they appear, to install CONTAMW on their computer. The CONTAMW icon (as depicted in the lower left hand corner of Figure 2) will be added to the Windows $®$ "Start" menu that will run the program CONTAMW.EXE.

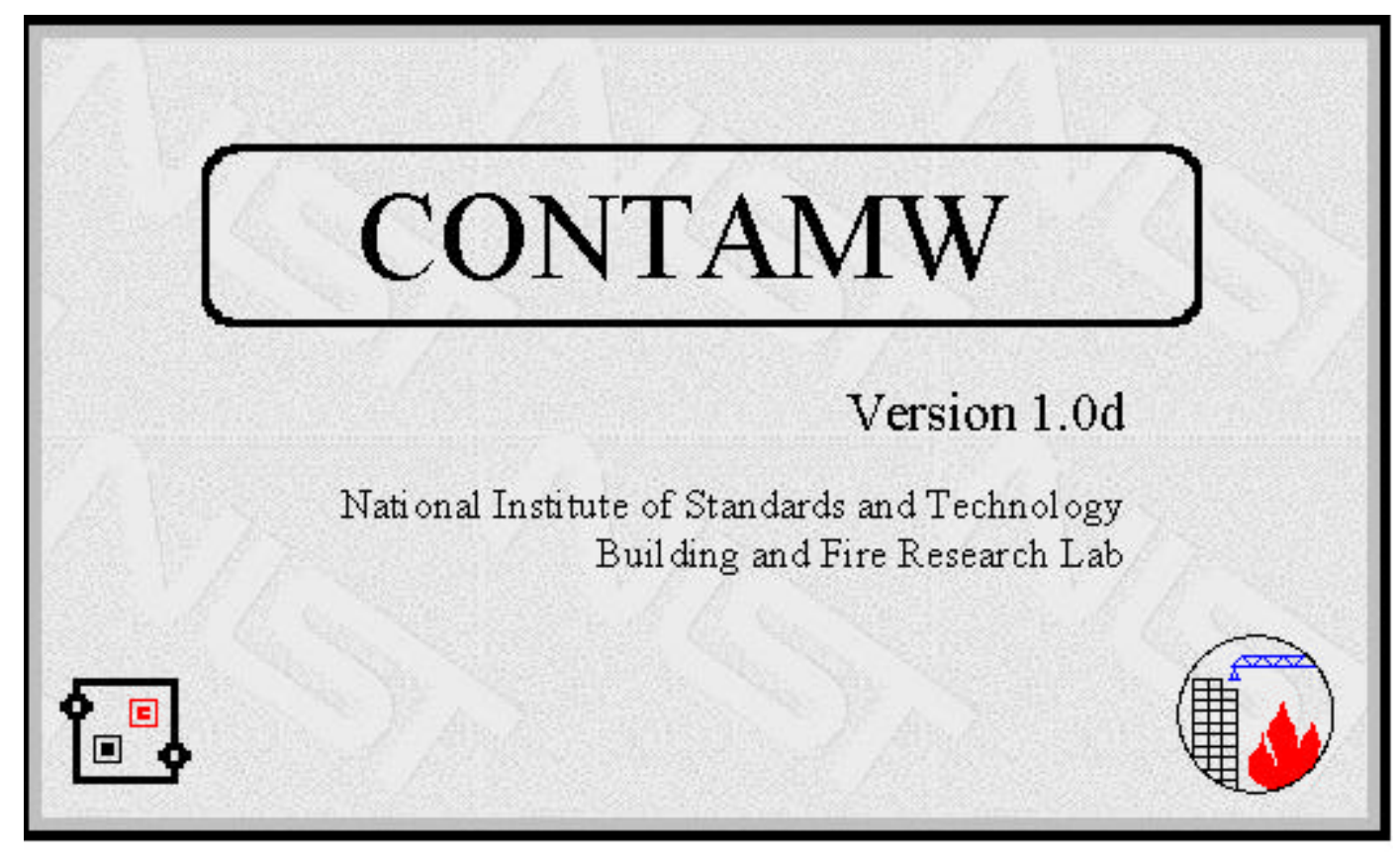

Figure 2 - CONTAMW Installation Splash Screen 


\subsubsection{Simulation Support Data}

Multizone modeling requires a potentially significant amount of detailed data to describe the building being modeled. This data includes building airtightness and component leakage, duct components, fans, contaminant source/sink data, wind pressure coefficients and schedules for various components such as ventilation system airflows and contaminant sources. There are many sources of this data including published literature, manufacturers data, and building specific measurements. The support data provided on this website is meant to simplify the use of CONTAMW by minimizing the amount of information the user is required to input into the CONTAMW program.

The support data on this website is provided in the form of CONTAMW library files. There are currently three types of library files available on the website: airflow elements, non-occupancy schedules, and wind pressure profiles. Using these pages one can view the contents of each library online, download individual library files, or simply download all libraries at once. Instructions are provide for copying and utilizing the library files with CONTAMW.

The following libraries are currently available. A detailed description of these libraries is available in Persily and Ivy [2001].

\section{Airflow Element Libraries}

ASHRAE Table of Residential Leakage Data - Effective leakage areas presented in Chapter 25 of the ASHRAE Fundamentals Handbook.

Miscellaneous Residential Leakage Data - A collection of residential leakage coefficients that have been used in previous modeling studies.

Summary of Commercial and Institutional Building Airtightness Data - A summary of a database of whole building envelope leakage values from the published literature.

Miscellaneous Commercial and Institutional Building Airtightness Data - Leakage values of commercial and institutional buildings primarily from measurements in individual buildings.

Schedule Library

Miscellaneous Schedules - Generic non-occupancy schedules used in previous modeling studies.

\section{Wind Pressure Profile Library}

Low-rise Building Wind Pressure Profiles - Wind pressure profiles for vertical walls of lowrise buildings having length-to-width ratios of one, two and three. 


\subsubsection{User Manual}

This page provides access to the CONTAMW 1.0 User Manual [Dols and Walton et al. 2000]. A copy of the manual can be downloaded as a post script definition file (PDF) and viewed using Adobe Acrobat Reader. A hard copy can be obtained by sending an email message to the Indoor Air Quality Group via the link provided on this page.

\subsubsection{List Server}

A list server is a system that maintains and provides access to a set of electronic discussion groups. A discussion group has been established on a list server to enable the discussion of CONTAM related topics. The list server resides on a third party server. Users of CONTAM can subscribe to the list server via a link on this page of the website. The list server then sends subscribers the list of messages as they appear on the server.

This web page provides a link to the third party list server. Following this link, you will be leaving NIST servers. NIST does not necessarily endorse the views expressed or the facts presented on the list server site. Further, NIST does not endorse any commercial products that may be advertised or available on the list server site.

\subsection{CONTAMPP}

CONTAMPP stands for CONTAM Post Processor. It is a software program designed to simplify the process of analyzing CONTAM simulation results. Specifically, CONTAMPP is used to calculate total airflow rates into user-selected zones of a building.

CONTAMPP enables the user to:

- Calculate total airflow into a user-selected set of zones

- Calculate building air change rates

- Calculate air entering through flow paths and ducts separately.

- Select which type of airflow elements to include when calculating totals. This enables, the user, for example, to calculate the amount of air entering a room through cracks and doors and exclude air entering though an air-handling system or ducts.

- Calculate average contaminant concentrations across selected zones.

- Perform these calculation for individual time steps and hourly averages of simulation results.

CONTAMPP can be downloaded via this page. The download file is an approximately 100 kilobyte self extracting archive (CONTAMPPZ.EXE) that is copied to the user's computer. Once downloaded, the user extracts two files by executing the self extracting archive and placing the files in the desired location within their computer directory structure. The two files are the Windows® program CONTAMPP.EXE and the help file CONTAMPP.CHM. 


\section{Applications of Multizone Modeling}

CONTAMW, and other multizone modeling programs, can be useful in a variety of applications to analyze building airflows, pressure differences and contaminant transport. Its ability to calculate building airflows is useful in assessing building air change rates, interzonal airflow rates and comparing ventilation strategies. The analysis of pressure relationships between building zones is particularly useful in analyzing smoke control systems. The contaminant transport simulation capabilities of CONTAMW can be useful for performing indoor air quality (IAQ) analysis including IAQ design, contaminant source isolation, IAQ forensics and exposure analysis. The following is a more detailed discussion of how CONTAMW can be used for these applications.

\subsection{Airflow and Ventilation}

One of the main reasons that the CONTAM family of programs was created was to estimate building air change rates. Air change rates can be affected by a variety of driving forces including weather (wind and indoor-outdoor temperature difference) and mechanical ventilation. CONTAMW provides the ability to establish fairly sophisticated multizone building geometries to simulate the effects of varying the driving forces upon the building and to provide insight into the interactions of weather, envelope and air handling systems. Some of the specific types of applications to which CONTAMW lends itself related to airflow and ventilation are outlined below.

\subsubsection{Building Air Change Rates}

The determination of building air change rates requires knowledge of airflow into a building both unintentionally through the envelope and intentionally by mechanical ventilation systems. Airflow into the building through the envelope is typically referred to as infiltration. The determination of air infiltration can be useful for a variety of purposes including the estimation of energy impacts due to building envelope leakage, the effects of weather and the effectiveness of natural ventilation systems. Knowing infiltration rates, outdoor weather conditions and desired indoor conditions, one can then estimate the contribution of infiltration to heating and cooling loads.

Infiltration analysis with CONTAMW requires the definition of leakage paths in the building envelope that are distributed vertically over each façade along with the definition of wind conditions at each façade. CONTAMW provides the ability to define leakage paths using several different models. These models provide the ability to define leakage paths based upon various physical descriptions of leakage paths such as cracks, orifices and leakage areas. Wind pressure can be set to be constant or variable for each envelope penetration.

CONTAMW also enables the analysis of mechanically induced airflows through the definition of mechanical ventilation systems. These systems affect building air change rates directly and indirectly. Direct affects include those due to the intake of outdoor air by an air handling system. Indirect affects are less obvious and can include duct leakage and relative zone pressurization/depressurization. CONTAMW provides three types of mechanical ventilation including fixed flow airflow paths, simple air handling systems and full duct models. These systems are described below in more detail. 


\subsubsection{Ventilation Strategies}

Along with the ability to analyze building air change rates, CONTAMW provides a rich set of tools to analyze different ventilation strategies of a building. Applications in this area include the ability to compare the use of different ventilation strategies within a given building, size air handling systems, and analyze natural ventilation systems and other strategies such as demand controlled ventilation.

\section{- Comparison of Ventilation Strategies}

CONTAMW enables the analysis of ventilation systems to determine the impacts on building airflows, pressure differences, and contaminant concentrations. A given building model can be easily reconfigured to compare different ventilation strategies within a given building geometry. CONTAMW provides several methods of simulating mechanical ventilation systems including: forced flow paths, a simple air handling system, and a duct system. Simple forced airflow paths can be defined to move air between adjacent zones at a fixed rate. For example, a bathroom exhaust fan or attic ventilation fan can be implemented to move air directly across the building envelope. The simple air handling system is provided to simplify the amount of data input relative to defining an entire duct system. This system enables the simulation of an air handler that can bring in varying amounts of outdoor air and recirculate and exhaust return air. It provides the ability to distribute the supply air to and return air from any building zone. The $d u c t$ system provides the most detailed method of modeling a mechanical ventilation system. An entire duct system can be defined including duct segments, junctions, transitions, terminals, dampers and fan performance curves. Each element of the duct system provides for the definition of friction losses, duct leakage and dynamic losses.

All of these ventilation systems can be configured to move air at varying rates according to userdefined schedules. For example, the fraction of outdoor air intake to the simple air handling system, fan on/off cycles and airflow rates through forced flow elements can be scheduled to deliver fractions of maximum user-defined values.

\section{Sizing Air Handling Systems}

CONTAMW can be used to size ventilation systems including the determination of airflow requirements to obtain relative pressurization of building zones or determining ventilation flow rates for whole house ventilation systems.

While CONTAMW is not a formal fan-sizing tool, it does lend itself well to an iterative approach of investigating multiple scenarios of building configuration and fan flow rates. It is fairly straightforward to establish building geometry and leakage characteristics for a given building within CONTAMW. Given required design conditions, e.g. minimum/maximum pressure differences between zones, one could use the ventilation system modeling capabilities to provide different airflow rates until these design conditions are met. Not only can the ventilation rate and delivery points be varied, but different envelope leakage characteristics can be investigated as well. Different leakage effects could include the opening and closing of doors and windows, construction tightness, building components with different leakage characteristics, or the use and placement of passive venting elements such as door transoms.

\section{\ Designing Natural Ventilation Systems}

Some of the fundamental aspects of designing a natural ventilation system are the geometry and orientation of a building and the sizing and placement of airflow paths to take advantage of 
prevailing weather conditions. CONTAMW provides the ability to model a building to account for these features. While CONTAMW cannot be used to determine the microscopic airflow and temperature fields within a given zone, it can be used to address the bulk pressure and flow relationships between the zones of a building. This can be quite useful in addressing the macroscopic design of a natural ventilation system [Axley 1999].

CONTAMW provides results in the form of airflow rates through each airflow (leakage) path that the user defines for a building. Using this feature one can perform simulations to investigate the differences in airflow rates obtained by varying different building features and weather conditions including the size and placement of ventilation openings in the building envelope, the orientation of the building to prevailing wind, the outdoor temperature difference and the size and location of ventilation stacks.

\section{a Demand Controlled Ventilation}

Demand controlled ventilation (DCV) involves the control of ventilation rates based on the monitoring of occupancy levels. As an alternative to monitoring occupancy levels directly, carbon dioxide $\left(\mathrm{CO}_{2}\right)$ is monitored since occupants are the dominant indoor source of $\mathrm{CO}_{2}$. CONTAMW can be helpful in addressing issues related to the design and operation of DCV systems [Musser 2000]. Given information on sources that might be found within a building, analysis can be performed to determine what contaminant levels might result based upon ventilation rates provided by a DCV system. Using CONTAMW, one could perform such an analysis while accounting for the complex airflows associated with a multizone building. This analysis could take on various forms. In its simplest form, one could estimate minimum ventilation rates by performing steady state analyses for a range of source strengths that are likely to be encountered and determine the ventilation rates required to achieve desired contaminant levels. While this simplified approach tends to ignore the time-dependant behavior of the DCV system and contaminant sources, it can provide a reasonable estimate of a minimum ventilation rate required to control the contaminant in question. Transient simulations could also be performed to better account for varying airflows, adsorption/desorption of contaminants and time varying contaminant concentrations.

\section{a Building Flush Out}

Another concern with DCV or any ventilation system that might minimize or shut off ventilation during unoccupied hours is the build up of non-occupant related contaminants during this socalled night set back period. CONTAMW can be useful in analyzing the levels of contaminant buildup that would occur under such situations and in determining the amount of ventilation required to purge, or flush out, the contaminants prior to occupancy [Musser 2000].

\subsection{Indoor Air Quality Analysis and Contaminant Transport}

The prediction of contaminant concentrations can be used to determine the indoor air quality performance of a building before it is constructed and occupied, to investigate the impacts of various design decisions related to ventilation system design and building material selection, and to assess the indoor air quality performance of an existing building. Predicted contaminant concentrations can also be used to estimate personal exposure based on occupancy patterns in a building.

As previously described, CONTAMW provides the ability to establish a model of the building geometry and modify other features of the building without having to redefine the building 
geometry. The features related to contaminant transport include sources, sinks and filtration systems. CONTAMW provides several different contaminant source models that enable the simulation of various contaminant emitting building materials (e.g. carpet, paint and pressedwood products), episodic type sources such as building maintenance activities and even pressure driven sources (e.g. radon entry through building foundations). Some of the applications related to contaminant dispersal in buildings to which CONTAMW lends itself are presented below.

As the name suggests, another main reason that the CONTAM family of programs was developed was to provide a tool for simplifying the analysis of airborne contaminant transport within complex, multizone buildings. Contaminant behavior within buildings can be influenced by a number of factors including airflow, source and sink properties, contaminant filtration by various building components and chemical reactions. CONTAMW provides for the ability to address all of these mechanisms within a single analysis tool. This comprehensive set of contaminant analysis features makes CONTAMW useful in understanding many contaminantrelated building issues and solving or preventing contaminant related problems in the built environment.

\subsubsection{IAQ Design Analysis}

Typically IAQ is dealt with during design by providing minimum ventilation rates on a space or whole building level. The prescriptive approach contained in ASHRAE Standard 62-1999 [ASHRAE 1999] provides minimum ventilation requirements in $\mathrm{L} / \mathrm{s}(\mathrm{cfm})$ per person or $\mathrm{L} / \mathrm{s} \cdot \mathrm{m}^{2}$ $\left(\mathrm{cfm} / \mathrm{ft}^{2}\right)$. The IAQ Procedure in Standard 62 is a performance-based procedure that addresses designing to maintain acceptable levels of known contaminants. CONTAMW can be useful in implementing this approach to designing for acceptable IAQ both from the point of view of ventilation system and building material impacts. Other features of IAQ design that can be addressed include the consideration of outdoor air contaminant levels, the potential use of contaminant filtration to treat outdoor and recirculated air, consideration of intermittent or variable occupancy, and distribution of ventilation air to multiple spaces.

\section{Ventilation System Impacts}

The first approach to IAQ design, referred to above, is the prescriptive Ventilation Rate Procedure in ASHRAE Standard 62. CONTAMW can be useful in implementing this design method and analyzing its impact on contaminant levels. CONTAMW can be used to model the provision of outdoor air intake rates prescribed by the procedure and to investigate various aspects of building performance including the analysis of contaminant levels realized from the existence of various indoor and outdoor contaminant sources.

CONTAMW could also be useful in analyzing how the building performs when accounting for the delivery of ventilation air to multiple spaces by a common supply air system. Once ventilation rates are calculated according to the "multiple spaces" method in the standard, the system flow rates of the CONTAMW model can be adjusted accordingly to analyze contaminant transport behavior under the "adjusted" conditions.

The Ventilation Rate Procedure also provides for the adjustment of ventilation rates to account for intermittent or variable occupancy within a building. Ventilation rates can be adjusted by changing damper positions or cycling the ventilation system fans on and off that deliver air to the intermittently occupied spaces. The variation in ventilation should be carried out in such a way as to maintain contaminant concentrations within acceptable levels at all times. The method by 
which the ventilation rate is varied depends upon the type of contaminant source that is being controlled, i.e., occupant related or not. The method involves lead or lag times of providing ventilation air depending on the type of source of the contaminant that is being controlled. CONTAMW can be used to model the source and develop contaminant profiles. From this information, ventilation control strategies can be implemented in the CONTAMW building model in the form of scheduled fan on/off times and system airflow rates. Simulations can be performed and results reviewed to determine if the ventilation strategy would maintain contaminant levels according to design requirements.

The second method of designing for IAQ is referred to as the Indoor Air Quality Procedure. Simply stated, the Indoor Air Quality Procedure consists of identifying known contaminants of concern, specifying acceptable levels of these contaminants and providing ventilation that prevents the acceptable levels from being exceeded. CONTAMW can be useful in analyzing contaminant levels based on contaminant source strengths, design ventilation rates and air filtration and cleaning system characteristics that might be implemented in the ventilation system design. Not only would CONTAMW be useful in verifying ventilation system design, it could also provide a means of documenting the design.

\section{a Building Material Impacts}

CONTAMW can be used to analyze the IAQ impacts of building material emissions. Although designers might implement "low-emitting" materials in a design, it is often difficult to quantify the effects of using such materials. CONTAMW enables the analysis of different materials within a building design on a quantitative basis.

\subsubsection{Contaminant Source Isolation}

Contaminant source isolation refers to the prevention of contaminant transport from one zone having a known source into another. Some examples of contaminant source isolation issues include parking garages, toilets and radon entry from the soil. These situations involve establishing airflow or pressure differentials between different zones of a building to control contaminant migration. The ability to use CONTAMW to define complicated multizone systems enables the analysis of contaminant transport not only between zones that are immediately adjacent to each other, but also the less obvious transport paths related to elevator and stair shafts, service chases and duct leakage.

One example of a CONTAMW source isolation problem is the analysis of radon entry into and transport within a building. CONTAMW provides a pressure-driven source model that can be used to effectively simulate the transport of radon from the soil into the building through cracks in a building foundation. Because the source is pressure dependant, the relationship between the pressure differences associated with different ventilation scenarios, stack and wind induced flows and radon transport into the building can be analyzed. Further, CONTAMW could then be used to investigate the implementation of various radon mitigation strategies including fan pressurization and depressurization techniques.

\subsubsection{IAQ Investigations}

CONTAMW can be useful in investigating IAQ problems as they occur in existing buildings. Using CONTAMW one can establish a building geometry and system features and use CONTAMW to gain insight into why a building is behaving the way it does. For example, if a room in a building is experiencing elevated contaminant levels from a known source, 
CONTAMW could be used to investigate potential transport paths and methods to mitigate the transport of the contaminant to occupied zones. CONTAMW analysis can be particularly useful when coupled with the measurement of relevant parameters such as system airflow rates, differential pressure, contaminant concentrations, wind and indoor and outdoor temperatures. CONTAM has been used as a tool to investigate building operating conditions that lead to radon entry from the soil and to size a fan system to alleviate the problem.

\subsubsection{Exposure Analysis}

Exposure analysis refers to the determination of the amount (dose) of a contaminant to which a building occupant would be subjected within a building. This analysis requires knowledge of contaminant concentration time histories, occupancy patterns within a building and occupant ingestion rates. CONTAMW provides the ability to calculate contaminant time histories using transient simulation techniques and to define occupant inhalation rates and occupancy patterns within a building. Together this information can be used to provide average and peak exposure levels as well as average and peak dosages of contaminants of concern.

\subsection{Smoke Management}

Smoke management is a term used to describe the methods implemented to passively or actively control the movement of smoke within the built environment in the interest of providing safety to occupants, fire fighters and property. Smoke management methods include compartmentation, dilution, pressurization, airflow and buoyancy [Klote and Milke 1992]. CONTAMW has been used to analyze many of these smoke management techniques. It has been used to simulate smoke movement in multizone facilities, to analyze the performance of smoke control systems including stairwell pressurization systems and to aid in the performance of tenability (occupant safety) analysis. Analysis of smoke management requires the consideration of the interaction of the many different building characteristics and driving forces that affect smoke movement.

It is important to realize that the main strength of CONTAMW lies in its ability to provide the analysis of different scenarios given an established building geometry, especially when that building geometry is fairly complex. CONTAMW is a valuable tool that can be very useful in designing and analyzing smoke management systems. Its use still requires the judgment of a skilled fire protection engineer familiar with smoke management design techniques such as outlined by Klote \& Milke [1992]. It is also important that the engineer is aware of the limitations of CONTAMW in capturing the near-field smoke transport phenomenon such as buoyancy driven flows due to the heat of the fire [Ferriera 1998].

The following is a brief description of the different methods that are currently considered when designing smoke management systems. These systems can be implemented individually or in conjunction with one another.

Compartmentation - Passive compartmentation refers to the use of physical barriers to hinder the movement of smoke from the fire space into the non-fire spaces. These barriers include walls, partitions, floors, doors and smoke dampers.

Dilution - Dilution of smoke typically refers to the removal of smoke from non-fire spaces to maintain acceptable levels of gas or particulates within the non-fire spaces. As the name implies, this method relies on the provision of make-up air to dilute the smoke or combustion gases that infiltrate a non-fire space as the air from that space is exhausted. 
Pressurization - Pressurization or smoke control refers to the use of mechanical ventilation systems (fans) to induce pressure differences across barriers having a relatively high resistance to airflow (i.e. small gaps) to control the movement of smoke between compartments. Stairwell and elevator shaft pressurization and zoned smoke control are typical implementations of the pressurization method.

Airflow - Smoke control by airflow is very similar to the pressurization method except that it typically refers to the flow of air through relatively large openings. This method is typically not implemented in buildings, but more commonly implemented for smoke control in transportation tunnels.

Buoyancy - Buoyancy refers to the venting of hot (buoyant) combustion gases through fanpowered and passive vents typically located in the ceiling of large, open spaces such as atria and covered shopping malls.

Following are some of the above applications for which CONTAMW can be useful in the design and analysis of smoke management systems.

\subsubsection{Stairwell Pressurization}

Stairwell pressurization systems are typically designed to maintain the stairwell at a higher pressure than the adjacent spaces to prevent infiltration of smoke into the stairwell. Typically, these systems are designed to maintain this pressure difference across closed stairwell doors; however, consideration is often given to the effects of open doors on this pressure relationship. The design and analysis of stairwell pressurization systems requires consideration of several different features including leakage characteristics of walls and doors, number and location of injection fans and compartmentation of stairwells. CONTAMW provides the ability to analyze these features by providing a generalized approach to defining vertical building configurations, leakage paths and fan systems.

Stairwell shafts can be defined by creating a series of zones located above one another interconnected with airflow paths using the stairwell model provided by CONTAMW. Each of the stairwell zones can then be connected to any adjacent zones using several leakage models provided by CONTAMW. These leakage models include doors, orifices and crack descriptions. Several methods of providing airflow to the stairwell are also available including constant volume and mass flow airflow elements, a fan performance curve element, and the simple air handling unit model. A duct system can even be implemented to distribute the air to different levels of the stairwell.

There are several features of CONTAMW that are quite useful when analyzing stairwell pressurization systems. The level copy feature of CONTAMW can save a lot of time when defining multiple building levels that are very similar in layout. This feature enables the detailed definition of a typical level that can then be duplicated and copied above or below any existing level. Modifications to the copied levels can then be performed as necessary. User-defined minimum and maximum pressure (or flow) limits can be associated with airflow paths. If the simulation results determine that these limits are exceeded, the flow path will be flagged on the SketchPad results display. Finally, a shaft report can be generated that shows the pressure drop, airflow rate and direction for two selected airflow paths on each floor of a vertical shaft in a graphical, easy to print report format. These features can be very useful in bringing potential areas of concern to the attention of the designer/analyst. 


\subsubsection{Zoned Smoke Control Systems}

Much like stairwell pressurization systems, zoned smoke control requires the analysis of interzonal airflows and pressure differences. CONTAMW provides the ability to establish the zonal geometry required to analyze the pressure and airflow relationships between smoke and non-smoke zones. The detail used to represent a building can range from very simple representations of smoke control zones as single-room zones to complex multiroom zones. Further, CONTAMW provides the ability to establish airflows to or from the required zones. Again, this can range from the more simple to complex approaches of using individual constant flow fan elements, simple air handling systems, or establishing a complete duct system. Having established a building geometry and air handling system, CONTAMW can be used to investigate different fire scenarios and smoke control strategies.

\subsubsection{Combined Systems}

Some smoke management systems implement combinations of the previously mentioned methods. For example, stairwell pressurization and zoned smoke control could be implemented within the same building. This combination of smoke management methods adds a level of complexity to the analysis of the smoke management system as a whole due to the potential interaction that can take place between the systems. CONTAMW can be quite useful in managing this complexity and providing insight into the interaction between systems.

\subsubsection{Tenability Analysis}

Another major aspect in the design of smoke management systems is tenability or maintaining conditions that provide for occupant (or equipment) safety during a fire. There are several different aspects of tenability including temperature, toxicity of and visibility through smoke. CONTAMW can be useful in the analysis of tenability particularly with respect to toxicity and visibility [Ferriera 1998]. The contaminant analysis features of CONTAMW can be used to establish smoke-related contaminants from which toxicity and visibility information can be gleaned. 


\section{$4 \quad$ Case Studies in Multizone Analysis}

CONTAM and other multizone modeling software are mostly used in the field of building ventilation and IAQ research. However, the use of multizone modeling in more practical applications is increasing. Along with building research, multizone modeling can be applied to areas of building design and operation. More specifically, applications include the design and performance analysis of ventilation, IAQ and smoke management systems.

The following are brief presentations of case studies of the application of CONTAM, including projects performed by both researchers and designers.

\subsection{Ventilation in Manufactured Houses}

[Persily 2000]

The HUD Part 3280, Manufactured Home Construction and Safety Standards [HUD 1994] contain requirements intended to provide adequate levels of outdoor air ventilation in manufactured homes. In the implementation of these standards, questions have arisen regarding the impact and significance of some of these requirements. Some of these questions relate to the actual ventilation rates in homes built to the standards and the means of providing supplemental mechanical ventilation to meet the requirements of the standards. Other questions have arisen as to how specific ventilation system components such as duct leakage, local exhaust fans and ventilation inlets affect ventilation rates, air movement patterns, and building pressures. In order to obtain some insight into these issues, CONTAM was used to simulate a doublewide unit under several different ventilation scenarios. These scenarios include envelope infiltration only, infiltration plus the effects of local exhaust and forced-fan operation, an outdoor air intake duct installed on the forced-air return, and whole house exhaust with and without passive inlet vents. Simulations were performed to predict outdoor air ventilation rates into the house due to infiltration and mechanical ventilation, interzone airflow rates between the rooms, building air pressures, and ventilation air distribution. Annual simulations were performed in three cities to assess ventilation rates and energy consumption associated with these scenarios. The results show that despite the assumption in the HUD standards that infiltration contributes $0.25 \mathrm{~h}^{-1}$ to the total ventilation rate, the predicted infiltration rates are lower than this value for many hours of the year. The supplemental ventilation systems investigated in this study provide ventilation rates that meet or exceed the total ventilation requirement of $0.35 \mathrm{~h}^{-1}$, but the impacts of such systems are dependent on their operating schedules. In addition, in these simulations, the impacts of a whole house exhaust fan are independent of whether this fan is located in the main living area or in a bathroom off the main living area. Also, for the case of ventilation with a whole house exhaust fan, the inclusion of passive inlet vents is not critical given the level of envelope airtightness used in these simulations. The results of these simulations are presented and discussed, and recommendations are made for changes to the HUD standards and for future research.

\subsection{Ventilation, IAQ and Energy Impacts of Residential Mechanical Ventilation}

[Persily 1998]

Based on concerns about indoor air quality and trends towards tighter envelope construction, there has been increasing interest in mechanical ventilation in residential buildings. A variety of ventilation approaches have been examined through both field measurements and computer simulation studies. This paper reports on a simulation study of indoor air quality, ventilation and 
energy impacts of several mechanical ventilation approaches in a single-family residential building. The study focused on a fictitious two-story house in Spokane, Washington and employed the multizone airflow and contaminant dispersal model CONTAM. The model of the house included a number of factors related to airflow including exhaust fan and forced-air system operation, duct leakage and weather effects, as well as factors related to contaminant dispersal including adsorption/desorption of water vapor and volatile organic compounds, surface losses of particles and nitrogen dioxide, outdoor contaminant concentrations, and occupant activities. The contaminants studied include carbon monoxide, carbon dioxide, nitrogen dioxide, water vapor, fine and coarse particles, and volatile organic compounds. One-year simulations were performed for four different ventilation approaches: a base case of envelope infiltration only, passive inlet vents in combination with exhaust fan operation, an outdoor intake duct connected to the forcedair system return balanced by exhaust fan operation, and a continuously-operated exhaust fan. Results discussed include whole building air change rates, air distribution within the house, heating and cooling loads, contaminants concentrations, and occupant exposure to contaminants.

\subsection{Energy Impacts of Infiltration and Ventilation in U.S. Office Buildings}

[Emmerich 1995, 1998]

The purpose of this study was to estimate the energy use in commercial buildings due to infiltration and ventilation airflows and to investigate the potential for energy savings that could be realized by envelope tightening efforts. A set of 25 buildings was used as a representative sample of the U.S. commercial building stock as of 1995. Buildings were located in cities throughout the U.S. so that a representative sample of climates was also taken into account. Leakage characteristics were assigned to each building based on limited envelope leakage data that exist for U.S. office buildings.

Infiltration airflows were estimated using CONTAM to account for the effects of weather and ventilation system airflows on infiltration. For each building, a relatively simple CONTAM model was created that consisted of three zones per floor - one for the main occupied area, one for the plenum, and one for the elevator and stairwell shafts combined. WYEC (Weather Year for Energy Calculation) weather data was obtained for each of the cities in which the buildings were located. A bin method was used to handle the large amount of data involved in the study. For each building, a set of simulations was performed based on bins of weather and ventilation airflow data to determine infiltration rates for each bin of data. These infiltration rates were then used in the form of a lookup table along with thermostat set points and inside-outside temperature difference (used to determine whether cooling, heating or free-cooling) to calculate hourly heating and cooling (both sensible and latent) loads attributable to infiltration.

The results of this study estimated that infiltration is responsible for about $15 \%$ of the total heating energy and $4 \%$ of the total cooling energy for U.S. office buildings. Results also indicated that potential energy savings on the order of $26 \%$ for heating load and $15 \%$ for cooling load could be realized by tightening building envelopes by $25 \%$ to $50 \%$. The study also revealed the difference in the contribution of infiltration to the heating and cooling load depending on whether the building was pressurized or depressurized with respect to the outdoors. 


\subsection{Modeling of Three Residential IAQ Control Options}

[Emmerich 1996]

NIST performed a study of the use of central forced-air heating and cooling system modifications to control IAQ in residential buildings. The objective of this effort was to provide insight into the use of multizone modeling to evaluate such modifications, the potential of these modifications to mitigate residential IAQ problems, the pollutant sources they are most likely to impact, and their potential limitations of the IAQ control strategies. Another important objective of the project was to identify issues related to the use of multizone IAQ models and to identify areas for follow-up work.

CONTAM was used to simulate pollutant concentrations due to a variety of sources in eight buildings with typical HVAC systems under different weather conditions. Baseline simulations were performed to determine contaminant levels prior to implementing IAQ controls, and then three IAQ control technologies were incorporated into the house models to determine their effectiveness in controlling the modeled pollutant sources. The IAQ control technologies included electrostatic particulate filtration, heat recovery ventilation, and an outdoor air intake damper on the forced-air system return.

Simulation results indicated that the system modifications reduced pollutant concentrations in the houses for some cases. However, the heat recovery ventilator and outdoor air intake damper increased pollutant concentrations in certain situations involving a combination of weak indoor sources, high outdoor concentrations, and indoor pollutant removal mechanisms. In cases where the IAQ controls reduced pollutant concentrations, they led to larger relative reductions in the tight houses than in the houses with typical levels of airtightness, though the typical houses still had lower post-control concentrations. The controls had the largest impact on concentrations of a non-decaying pollutant from a constant source. Limited system run-time under mild weather was identified as a limitation of IAQ controls that operate in conjunction with forced-air systems.

\subsection{IAQ Impacts of Particle Air Cleaners in a Single-zone Building}

[Emmerich 2000]

This case study was an initial phase of an effort to evaluate the ability of multizone airflow and pollutant transport models to predict the impact of residential particulate air cleaning devices. Measurements of the performance of several particulate air cleaning devices and related particle transport parameters were performed in a one-room test house. These measurements were used to calculate building air change rates, particle deposition rates and penetration factors, and air cleaner removal efficiencies. Two separate $24 \mathrm{~h}$ tests were performed with two of the tested air cleaners, and the measured air change rates and particle concentrations were compared to predicted values obtained with the CONTAM model. For both tests, simulated $24 \mathrm{~h}$ average air change rates were within $5 \%$ of measured air change rates and simulated $24 \mathrm{~h}$ average particle concentrations were within $30 \%$ of measurements for all particle sizes. Simulations were also performed to predict the impact of the air cleaners compared to a typical furnace filter. 


\subsection{Radon Transport in Large Buildings}

[Fang 1995]

Computer simulations of airflow and radon transport in four large buildings were performed using CONTAM. The buildings modeled included a twelve-story multi-family residential building, a five-story mechanically ventilated office building with an atrium, a seven-story mechanically ventilated office building with an underground parking garage, and a one-story mechanically ventilated school building. Interzone airflow rates and radon concentrations were predicted in these buildings as a function of wind speed and direction, indoor-outdoor temperature difference, and ventilation system operation. Ventilation system factors that were studied included the operation of exhaust fans in the apartment building and variations in the percent outdoor air intake in the office buildings. Simulations in the office buildings were also made with the ventilation systems off and with variations in the balance of the supply and return airflow rates.

\subsection{IAQ Design}

[Musser 2000]

Increased public awareness and changing industry standards have highlighted the importance of indoor air quality in the building design process. At the same time, many owners would like to construct buildings that conserve energy and minimize environmental impact. To accomplish both of these goals, the designer must be able to understand airflow rates, pressure relationships, and contaminant transport in buildings. This case study describes the use of a CONTAM to perform design calculations for a new building on a college campus in the United States. The building incorporates a number of environmentally "progressive" features such as natural ventilation, energy recovery, a biological wastewater treatment process, and $\mathrm{CO}_{2}$ demand controlled ventilation. CONTAM was used to size an exhaust fan for source isolation, select minimum ventilation quantities to control building related contaminants, and specify procedures for flushing out contaminants prior to occupancy. CONTAM was also used to predict transient contaminant levels, taking into account weather and associated infiltration. The generalization of these design and analysis techniques to a wider range of indoor air quality design applications is also discussed.

\subsection{Air Balance Analysis}

[Unpublished]

A multizone model of a laboratory facility of the Westinghouse Savannah River Company was developed in order to analyze current operating characteristics of the supply and exhaust ventilation system and investigate proposed modifications to the ventilation system. The facility consists of three buildings comprised of office, laboratory and corridor spaces. The ventilation system is a once-through system designed to prevent air movement from more "clean" spaces to less "clean" spaces, e.g. air should not be allowed to flow from the laboratories to the office spaces. For this project, the entire duct system was implemented in CONTAM. This was the most extensive duct system ever implemented using CONTAM to date. Fan curves were implemented in CONTAM based on manufacturer fan curve specifications.

The air balance between different zones of the facility was analyzed under various operating conditions of the ventilation system supply and exhaust fans including fume hoods to determine 
proper direction of airflow between zones. A base case was developed based on normal operating conditions of the current ventilation system. This case revealed that operating characteristics were in line with desired performance with respect to relative space pressurization. Other cases were developed to investigate air balance conditions when certain fans were shut off for maintenance purposes or when a process upset condition occurs in the facility during which corresponds to a minimal exhaust-only condition. Another case involved the modification of fume hoods in one of the laboratory spaces. Among the findings of this project, the simulations revealed that some of the fan-off conditions could lead to undesirable differential pressures between clean and less-clean spaces, the process upset condition requires more makeup air than currently available, and that the proposed fume hood modifications would not be supported by the current duct system.

\subsection{Smoke Management}

\section{[Ferriera 1998]}

This case study involved the analysis of a smoke management system in a large multi-building complex. Fire protection engineers investigated the interzonal airflows and pressure differences that would be produced by the activation of zoned smoke control systems and the far-field tenability conditions that might exist under various fire scenarios. One of the buildings in the complex was represented within CONTAM as having over 100 levels, more than 3,000 zones and over 10,000 airflow paths connecting the zones.

CONTAM was not developed with near-field fire modeling in mind, so the users had to develop creative ways to simulate near-field smoke transport. For example, buoyancy-induced flow due to a fire was modeled by creating a contaminant zone around the fire region and implementing fan-flow elements to simulate the ceiling jets caused by smoke plumes impinging on the ceiling. The contaminant within the zone in this case was a generic contaminant called "smoke." Naturally, great care must be taken when implementing the model in this way, but the method established proved to be quite useful to the users.

One objective of the project was to investigate the performance of a zoned smoke control system that was being planned for a part of a renovation project. CONTAM's simple air handling systems were used to model fifteen HVAC/smoke control zones containing supply and return air handling systems, retail and food area supply and exhaust systems, kitchen exhaust systems and smoke control systems. Many different simulations were performed to evaluate the performance of the smoke control systems under varying HVAC and smoke system operating modes for different fire scenarios. This analysis revealed some unexpected interactions between the smoke control systems and the HVAC systems.

Tenability analysis was used to estimate safe refuge distances from smoke spread. Two tenability criteria were established - one for visibility distance and another for carboxyhemoglobin levels. Visibility and carboxyhemoglobin levels were calculated based upon the concentration of smoke and carbon monoxide, respectively, generated from a given mass of fuel burned. 


\section{$5 \quad$ Publications}

This section of the website contains a bibliography of approximately 200 multizone modeling related publications. NIST publications are available for download from this website in their entirety as postscript definition files (PDF) and can be viewed using Adobe Acrobat $₫$ Reader.

The bibliography can be viewed online or downloaded as either a Microsoft $\circledast$ Word document file, text file, or EndNote ${ }^{\circledR}$ bibliographical library file.

\section{Future Plans}

This report presents the current status of the website. NIST plans to extend and continuously evolve the contents to better address the needs of the building industry. The next version of the website will include enhanced capabilities of CONTAMW, a weather file processor, more detailed information on case studies including actual CONTAMW project files that can be downloaded by the user, and a more detailed tutorial containing actual project files. Some potential enhancements to CONTAMW include: implementing the ability to vary indoor zone air temperatures according to user-defined schedules, implementing the ability to model building controls that would provide the capability to simulate the response of ventilation systems to various changes in building conditions (e.g. change airflow rates in response to contaminant levels), handling non-trace contaminants to improve modeling capabilities of contaminants that can affect the density of indoor air (e.g. moisture and smoke), implementing a general spline airflow element that will improve CONTAM's ability to handle the simulation of natural ventilation systems, and updating the solver to increase numerical stability and provide for the implementation of the general spline airflow element. The new weather file processor will enable the user to create CONTAMW weather files and convert existing weather file formats such as TMY and WYEC into CONTAMW weather files. 


\section{$7 \quad$ References}

ASHRAE (1999). ASHRAE Standard 62-1999 Ventilation for Acceptable Indoor Air Quality, ASHRAE.

Axley, J. (1999). Passive Ventilation for Residential Air Quality Control. ASHRAE Transactions 105(2).

Emmerich, S. J., A. K. Persily, et al. (1995). A Workplan to Analyze the Energy Impacts of Envelope Airtightness in Office Buildings, National Institute of Standards and Technology. NISTIR 5758.

Emmerich, S. J. and A. K. Persily (1996). Multizone Modeling of Three Residential Indoor Air Quality Control Options, National Institute of Standards and Technology. NISTIR 5801.

Emmerich, S. J. and A. K. Persily (1998). Energy Impacts of Infiltration and Ventilation in U.S. Office Buildings Using Multizone Airflow Simulation. IAQ and Energy 98, New Orleans, Louisiana, ASHRAE.

Emmerich, S. J. and S. J. Nabinger (2000). Measurement and Simulation of the IAQ Impact of Particle Air Cleaners in a Single-Zone Building, National Institute of Standards and Technology. NISTIR 6461.

Fang, J. B. and A. K. Persily (1995). Computer Simulations of Airflow and Radon Transport in Four Large Buildings, National Institute of Standards and Technology. NISTIR 5611.

Ferriera, M. J. (1998). Analysis of Smoke Control System Design Using a Computer-based Airflow Analysis. Pacific Rim Conference and Second International Conference on PerformanceBased Codes and Fire Safety Design Methods, Maui, Hawaii.

HUD. (1994). Part 3280, Manufactured Home Construction and Safety Standards. U.S. Department of Housing and Urban Development.

Klote, J. H. and J. A. Milke (1992). Design of Smoke Management Systems. ASHRAE.

Musser, A. (2000). Multizone Modeling as an Indoor Air Quality Design Tool. Proceedings of Healthy Buildings 2000, Espoo, Finland.

Persily, A. K. (1998). A Modeling Study of Ventilation, IAQ and Energy Impacts of Residential Mechanical Ventilation, National Institute of Standards and Technology. NISTIR 6162.

Persily, A. K. and S. R. Martin (2000). A Modeling Study of Ventilation in Manufactured Houses. National Institute of Standards and Technology. NISTIR 6455.

Persily, A. K. and E. M. Ivy (2001). Input Data for Multizone Airflow and IAQ Analysis. National Institute of Standards and Technology. NISTIR 6585. 


\section{Acknowledgments}

The author would like to acknowledge the creative and "webmasterful" cooperative education student Michael Huang of the University of Maryland and student intern Eric Tai of Thomas S. Wootton High School for their invaluable assistance in the development of the website. 